\title{
Development of an Anthropometric Database Representing the Singapore Population
}

\author{
Heow Pueh LEE ${ }^{* 1}$, Saurabh GARG ${ }^{1}$, Nicolette $\mathrm{CHHUA}^{2}$, Frederick TEY ${ }^{2}$ \\ ${ }^{1}$ Department of Mechanical Engineering, National University of Singapore, Singapore; \\ ${ }^{2}$ Defense Medical \& Environmental Research Institute, DSO National Laboratories, Singapore
}

DOI: 10.15221/15.234 http://dx.doi.org/10.15221/15.234

\begin{abstract}
Anthropometric design is one of the most important disciplines within the area of ergonomic approaches. The objective of this study is to develop and establish an anthropometric database that represents the Singapore population. The database collected would be useful for other potential applications such as the local retailed industry for apparels, shoes, vehicles and furniture; transport industry for the decision on cabin and seat sizes, and also many major and large corporations with large number of employees. More than 2000 Singapore citizens and Permanent Residents will be recruited from the public to take part in this survey. Age and gender will be sampled independently per age and gender group in a total of 5 age groups (16-20, 21-30, 31-40, 41-50 and 51-60). Racial/ethnic strata will not be controlled but will be reported as part of the biographical data. Body measurements are taken with a combination of traditional anthropometric tools and three-dimensional body and foot scanner. The subject's feet and hand are scanned using a Delcam iQube foot scanner. The subject's body is scanned in six postures using the VITUS Smart XXL 3D Body Scanner. In this paper, we will report some interesting findings arising from this anthropometric study on demographics, foot and shoe sizes and also the ergonomic study of chairs in two large lecture theatres and the seats of internal shuttle buses plying the campus.
\end{abstract}

Keywords: Anthropometric study; 3D imaging; 3D foot scanning, statistical analysis

\section{Introduction}

Ergonomic design is an important aspect for both service and manufacturing industries. For these industries, the productivity as well as work place safety would be dependent on how humans interact with the machines, gadgets, equipment and the work place environment such as layouts and furniture designs. Anthropometric design is one of the most important disciplines within the area of ergonomic studies. With the correct anthropometry layout, products and working tools can be used safely, comfortably and efficiently. Over the last decades, human body metrics have been used to improve human-product interaction namely ergonomic designs of product or procedure designs (Trieb et al., 2013). Ergonomic designs are also important for many other industries. Examples include transport industry for deciding the optimal size of the seats for passengers cars, trains and aircrafts (https://dspace.lboro.ac.uk/2134/701); apparel industry for deciding on the stocks for production (Ashdown et al.,2004); furniture industry for deciding on the sizes for tables and chairs (Parcells et al., 1999); footwear industry for the design of orthoses, prostheses and manufacturing of different types of socks (Sarghie et al., 2013), work design for aircraft maintenance (Drury 1998) and others.

New technologies for the gathering, storage and analysis of anthropometric data have enhanced the availability of digital anthropometric resources. Since 1999, more than 16 large-scale national 3D body scanning surveys have been conducted around the world. The availability of these data has created the opportunity to exploit shape information beyond today's 1D-measurement based methodologies. Many countries have been making great efforts in establishing an anthropometric database for different population groups such as civilians, fire fighters, military personnel, students, and workers (Bolstad et al., 2001; Wang et al., 2002). Since 1999, more than 16 large-scale national 3D body scanning surveys have been conducted around the world. The earlier anthropometric studies are typically done manually. CAESAR (Civilian American and European Surface Anthropometry Resource) was the first survey which used a 3D body scanner to acquire 3D scans of body surfaces, as well as demographics data and traditional measurements. In 1999 and 2000, 11,000 subjects in Great Britain were scanned and manually measured (SizeUK). The "next step of evolution" was made in France in 2003-2005. 11,562 subjects were scanned using a new technology, so parallel manual measurements were no longer used. The Swedish survey of 2004/2005 scanned more than 4,000 subjects, using the

*mpeleehp@nus.edu.sg, +65-65162205; www.me.nus.edu.sg 
same technology and concept as the French survey. 2007 saw the initiation of several body scanning surveys in other countries like Spain and China. A new survey was also started in Germany SizeGERMANY, where more than 12,000 women, men and children where measured at more than 30 different scanning locations. The primary requirement on anthropometrical surveys is the representation of the entire population. In most of the survey carried out manually, two tenths of one percent of the population was regarded as being representative.

The Department of Mechanical Engineering, National University of Singapore has been engaged in a large scale Anthropometric survey (in Singapore context) involving more than 2000 Singapore residents. For the study, age and gender of the volunteers have been sampled equally per age and gender group in a total of 5 age groups (16-20, 21-30, 31-40, 41-50 and 51-60). Racial/ethnic strata will not be controlled but will be reported as part of the biographical data. Body measurements will be taken with a combination of traditional anthropometric tools and a three-dimensional body scanner (The VITUS Smart XXL body scanner). A list of body landmarks, postures, dimensions and definitions were elicited from international standards such as ISO 7250, ISO 8559, and DOD-HDBK-743A. Biographical data will be gathered to characterize the demographic composition of the database.

The objective of the Singapore Anthropometric survey is to develop and establish an anthropometric database that represents the Singapore population. The survey is the first known major anthropometric study on Singapore population using 3D imaging techniques. The database will provide valid and current anthropometric criteria for procurements and efficient design and sizing tariffs of hardware and equipment. The database collected would be useful for the local retailed industry for apparels, shoes, vehicles and furniture; transport industry for the decision on cabin and seat sizes, and also many major and large corporations with large number of employees for their logistic considerations. It would also be of interest to research institutes or companies in terms of product and equipment designs, work flow and process optimization, human-machine interactions and many other potential processes or functions such as maintenance processes that involve human interaction. In this paper, we will present how the large scale anthropometric studies using the 3D imaging systems were setup and organized and the data collection process. Some preliminary findings from the statistical analysis of data collected so far will also be presented.

\section{Methodology}

\subsection{Facility setup and IRB approval}

A room within Block EA, Faculty of Engineering conveniently situated near the main entrance of the university was used for setting up the scanning facilities for the study. The room was selected as the building is next to a bus stop along Clementi road as well as the main entrance to the university so that the volunteers can easily locate the place. The necessary IRB approval for the study was obtained in October 2013. The IRB was modified slightly several times during the course of the study. The latest amendment was approved in June, 2015.

A website ${ }^{1}$,describing the study in detail was created to facilitate the recruitment of subjects online. Minors ( $<21$ years) can download the parental consent form to be signed by their parent or legal guardian from the website. The website also contains the direction to come to the experimental mechanics laboratory for scanning.

The relevant approval from the Institutional Review Board has been obtained for the study (NUS-IRB Reference code: 13-430).

\subsection{D imaging equipment and collection of data}

For the Singapore anthropometric study, each subject is scanned using the VITUS Smart XXL 3D Body Scanner (Figure 1) in six postures (Figure 2). Besides the full body laser scanner, the Delcam iQube foot scanner was used to collect the 3D surface of the right foot as well as the right hand (Figure 3 ). The procedure of that a subject comes for scanning is as follows:

- The subject first show his/her IC to verify that he/she is Singaporean or Permanent Resident. Males are asked to show their identity cards.

- Operator (who is of same sex as the subject) first briefs about the study to the subject and the subject is given a chance to ask any questions.

- Once the subject is satisfied with answers to all his/her questions, he/she signs the consent form.

\footnotetext{
${ }^{1}$ http://dynamicslab.mpe.nus.edu.sg/AnthroScan/
} 
- Subject fills in the questionnaire.

- Data collection starts with operator first measuring all manual data points.

- Operator scan subject's right hand and right foot using Delcam iQube scanner.

- Subject changes into swimming cloths.

- Operator scan the subject in six postures.

- Subject changes back to his/her cloths.

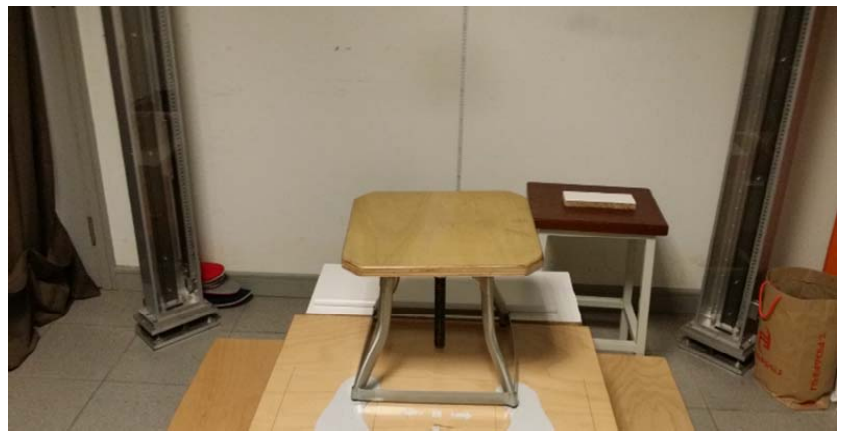

Figure 1: VITUS Smart XXL 3D Body Scanner, The other two columns are not in the picture.
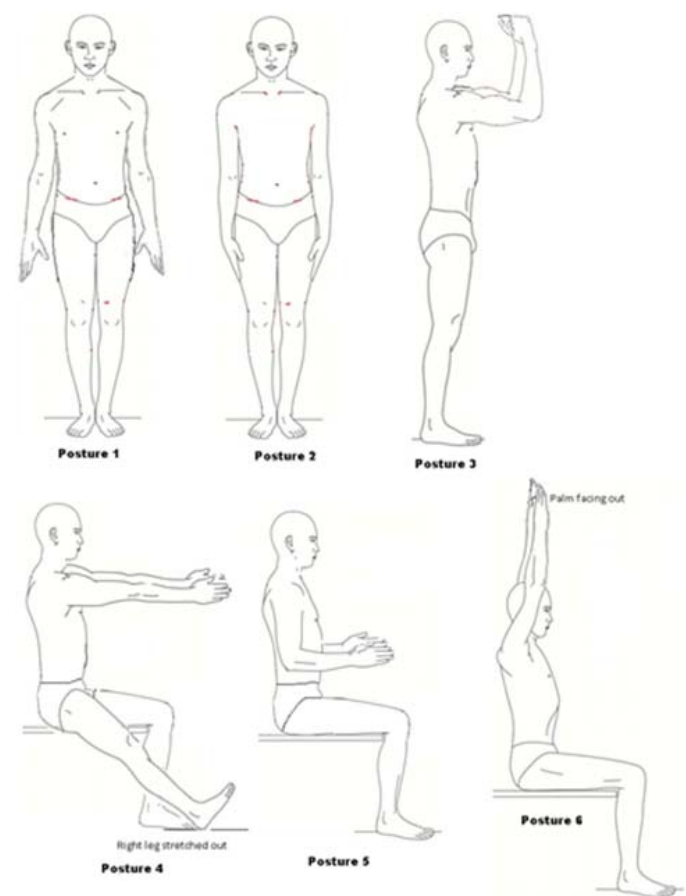

Figure 2: The six postures to be scanned

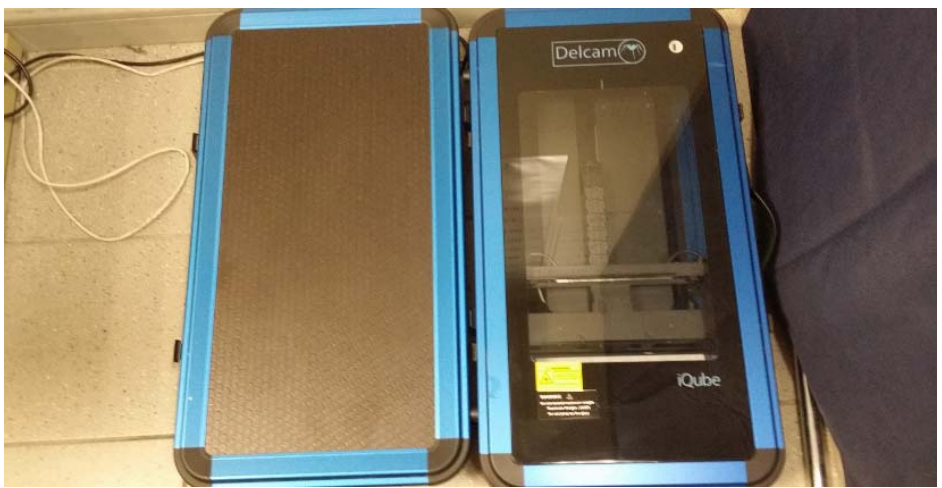

Figure 3: The 3D foot scanner for scanning of plantar contours 


\section{Preliminary Findings and Discussion}

\subsection{Demographics}

We have scanned 240 males and 240 females each in two of the age groups: $16-20$, and $21-30$. The distribution of weight, height, and BMI are summarized in the following box plots. The current results are consistent with the reported results (Business Insider, 2014) of average height of Singapore males as $171 \mathrm{~cm}$ and Singapore females as $160 \mathrm{~cm}$.
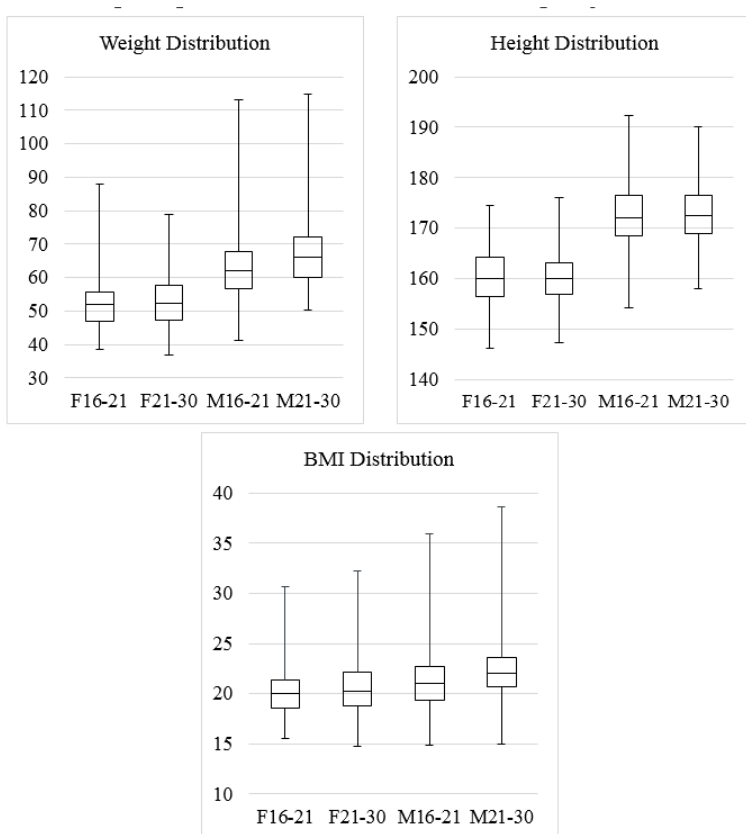

Figure 4: Weight, height and BMEl distribution of the two age groups from 16-30.

\subsection{Foot size analysis}

The shoe size is determined from foot length (from heels to the biggest toe) using the following table:

Table 1 Classification of foot size

\begin{tabular}{rrrr}
\hline \multicolumn{2}{c}{ Females } & \multicolumn{2}{c}{ Males } \\
\hline Length & US Size & Length & US Size \\
\hline 22.1 & 5 & 23.7 & 6 \\
22.4 & 5.5 & 24.1 & 6.5 \\
22.9 & 6 & 24.6 & 7 \\
23.3 & 6.5 & 24.9 & 7.5 \\
23.7 & 7 & 25.4 & 8 \\
24.1 & 7.5 & 25.9 & 8.5 \\
24.6 & 8 & 26.2 & 9 \\
24.9 & 8.5 & 26.7 & 9.5 \\
25.4 & 9 & 27.1 & 10 \\
25.9 & 9.5 & 27.5 & 10.5 \\
26.2 & 10 & 27.9 & 11 \\
26.7 & 10.5 & 28.4 & 11.5 \\
27.1 & 11 & 28.7 & 12 \\
27.5 & 11.5 & 29.2 & 12.5 \\
27.9 & 12 & 29.7 & 13 \\
& & 30.0 & 13.5 \\
& & 30.5 & 14 \\
& & 31.0 & 14.5 \\
& & 31.3 & 15 \\
\hline
\end{tabular}


The following four charts summarized the distribution of foot length and shoe sizes for females and males for two age groups: $16-20$ and $21-30$.

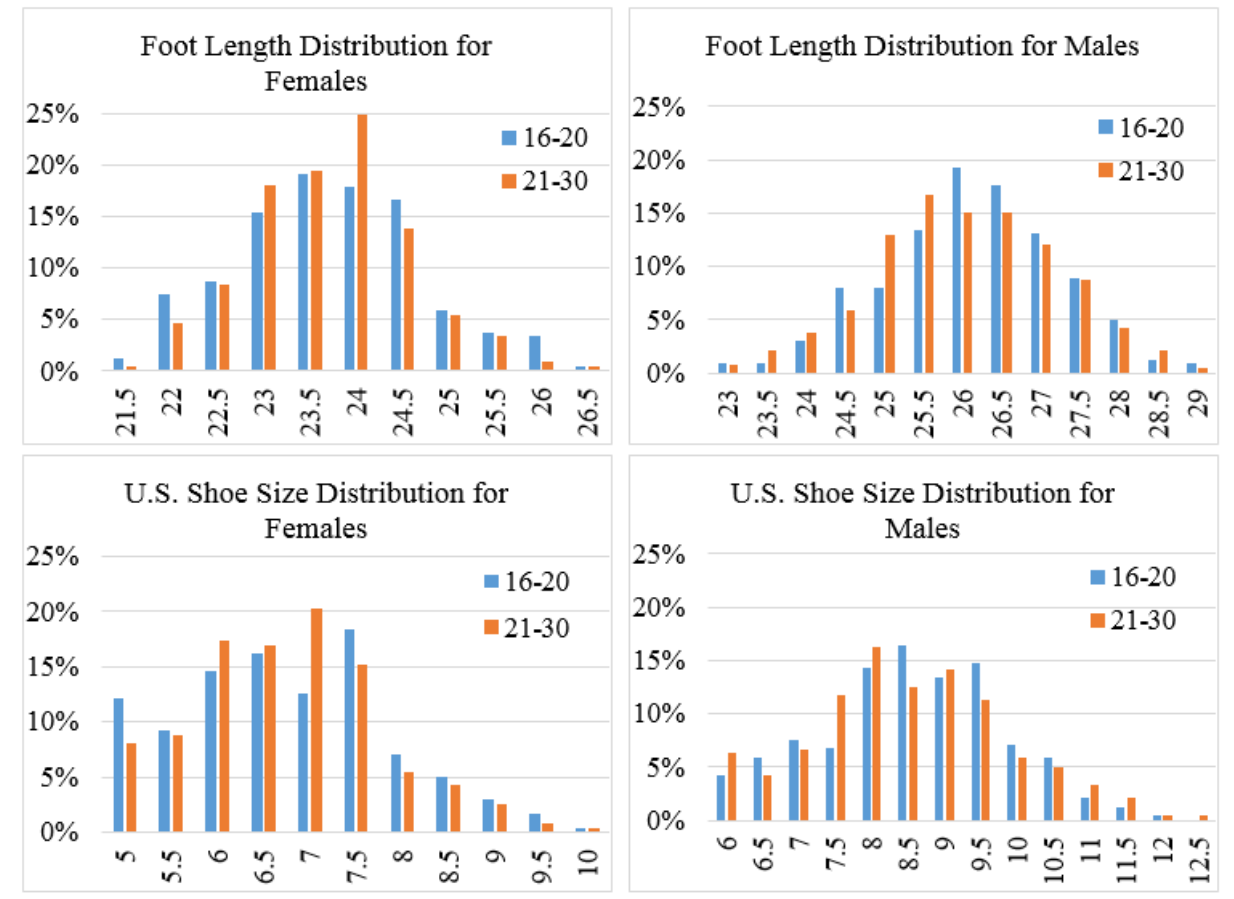

Figure 5: Foot size distribution of the two age groups from 16-30.

For each shoe sizes, there are two possible shoe widths: standard and wide. The two charts below summarized the distribution of shoe widths for all females and males.
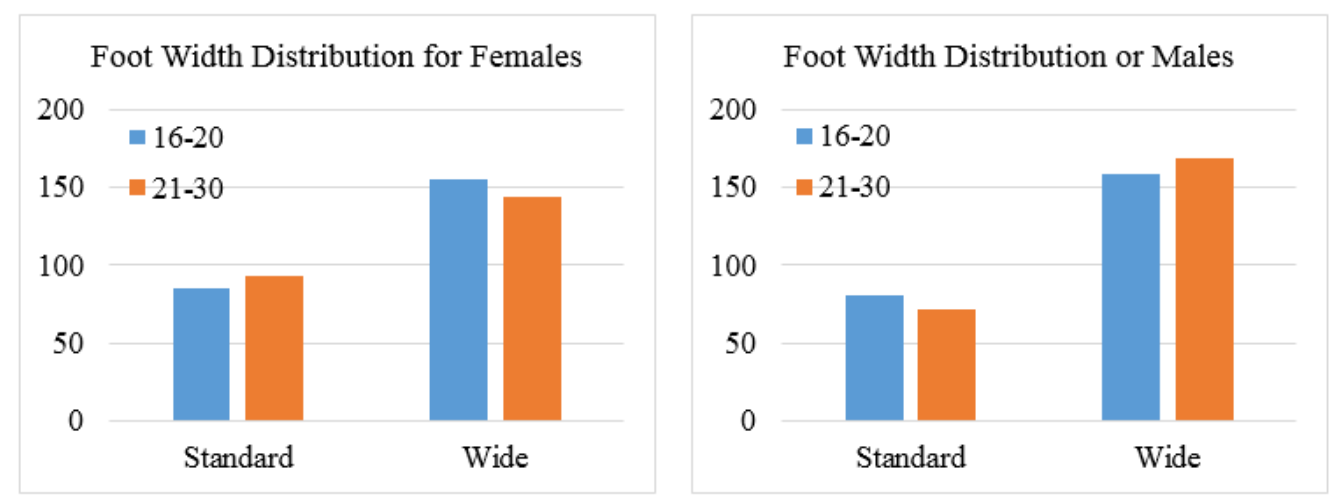

Figure 6: Shoe width distribution of the two age groups from 16-30

\subsection{Ergonomics Study for chairs}

A preliminary study to test the suitability of the chairs in Engineering Auditorium and Lecture Theatre 7 (both in block EA in the faculty of engineering) and seats in the two of the internal shuttle buses in NUS were conducted. We measured three parameters from the chairs: width, depth, and height and compared them to the size of people scanned.

\subsubsection{Chair width}

To sit comfortable in a chair, the chair width should be more than the hip width of a person. We have found that all the chairs we measured have enough width to accommodate most of the people. The results indicating the number of people who can sit comfortably on the chair are summarized in the following table (Table 2). 
Table 2: Ergonomic study of chair width

\begin{tabular}{|l|r|r|}
\hline Location & $\begin{array}{c}\text { Percentile } \\
\text { Females }\end{array}$ & $\begin{array}{l}\text { Percentile } \\
\text { Males }\end{array}$ \\
\hline Auditorium & $1000 \%$ & $99.9 \%$ \\
\hline LT7 & $98.7 \%$ & $97.2 \%$ \\
\hline Shuttle Bus 1 & $97.4 \%$ & $95.7 \%$ \\
\hline Shuttle Bus 2 & $98.1 \%$ & $96.5 \%$ \\
\hline
\end{tabular}

\subsubsection{Chair Depth}

To properly support one's back while sitting on a chair, the distance between buttock and popliteal (a point directly behind the knee) should be more than the chair depth. The results based on this criterion are summarized in the following table.

Table 3: Ergonomic study of chair depth

\begin{tabular}{|l|c|c|}
\hline Location & $\begin{array}{l}\text { Percentile } \\
\text { Females }\end{array}$ & $\begin{array}{l}\text { Percentile } \\
\text { Males }\end{array}$ \\
\hline Auditorium & $62.9 \%$ & $75.4 \%$ \\
\hline LT7 & $80.4 \%$ & $86.5 \%$ \\
\hline Shuttle Bus 1 & $90.4 \%$ & $94.4 \%$ \\
\hline Shuttle Bus 2 & $90.4 \%$ & $94.4 \%$ \\
\hline
\end{tabular}

\subsubsection{Chair Height}

Ergonomics recommendation to sit comfortably in chair is to make sure that upper legs are horizontal and lower legs are vertical and foot should be resting on the floor. Using this as a guideline, we compared the chair height in the four places from the data collected (chair height of two shuttle buses is same that of engineering auditorium). We found that most of the chairs are too high for majority of people. The problem is more prominent for females than males as they are shorter the males. The table below summarized the results:

Table 4: Ergonomic study of chair height

\begin{tabular}{|l|c|c|}
\hline Location & $\begin{array}{l}\text { Percentile } \\
\text { Females }\end{array}$ & $\begin{array}{l}\text { Percentile } \\
\text { Males }\end{array}$ \\
\hline Auditorium & $7.1 \%$ & $22.4 \%$ \\
\hline LT7 & $14 \%$ & $31.6 \%$ \\
\hline
\end{tabular}

We also calculated how high a person's feet will be from the ground and the results are presented in Table 5. It shows that the Chairs in EA auditorium is too high for a significant proportion of females. .

Table 5: Height of the feet from ground

\begin{tabular}{|c|c|c|c|c|c|c|c|}
\hline & & $1 \mathrm{~cm}$ & $2 \mathrm{~cm}$ & $3 \mathrm{~cm}$ & $4 \mathrm{~cm}$ & $5 \mathrm{~cm}$ & $6 \mathrm{~cm}$ \\
\hline EA & Females & $86.5 \%$ & $80.0 \%$ & $67.9 \%$ & $48.3 \%$ & $30.0 \%$ & $18.5 \%$ \\
\hline LT7 & Females & $80.0 \%$ & $67.9 \%$ & $48.3 \%$ & $30.0 \%$ & $18.5 \%$ & $8.8 \%$ \\
\hline EA & Males & $69.2 \%$ & $56.9 \%$ & $42.7 \%$ & $28.8 \%$ & $16.9 \%$ & $8.8 \%$ \\
\hline LT7 & Males & $56.9 \%$ & $42.7 \%$ & $28.8 \%$ & $16.9 \%$ & $8.8 \%$ & $4.4 \%$ \\
\hline
\end{tabular}


The chairs in Engineering auditorium (Figure 7) is meant for external visitors and are in general larger than the normal chairs in Lecture Theatre (LT7). This is the main reason as to why the chairs are too high for the students.

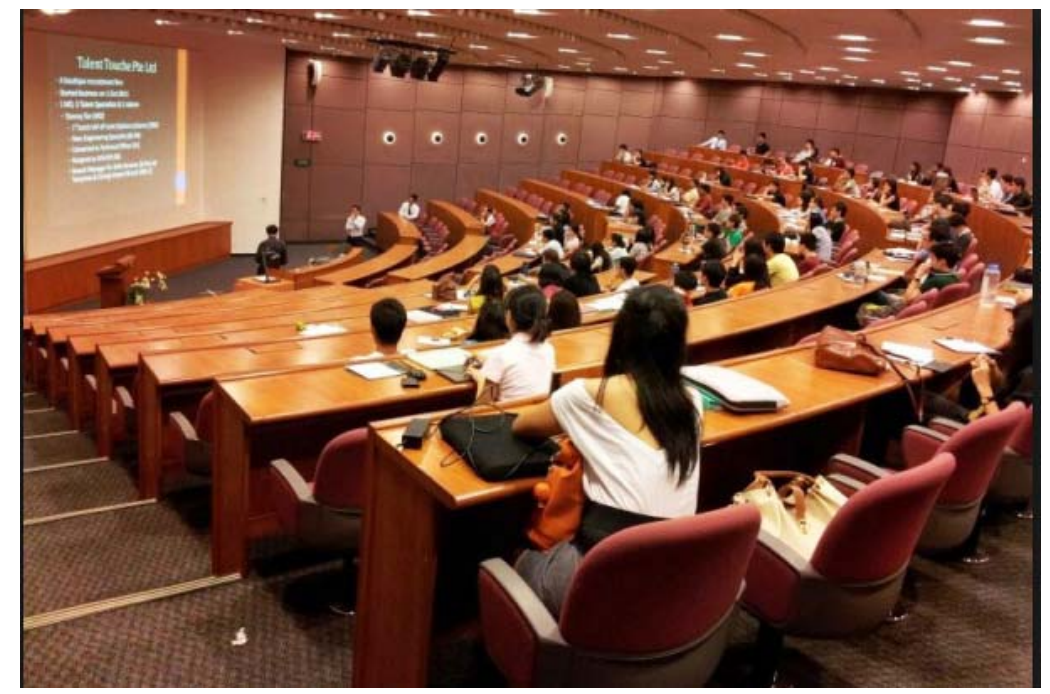

Figure 7: Chairs in Engineering auditorium.

On the other hand, the chairs in LT7 are smaller and are meant for students taking large classes. The chairs are more suitable for the students.

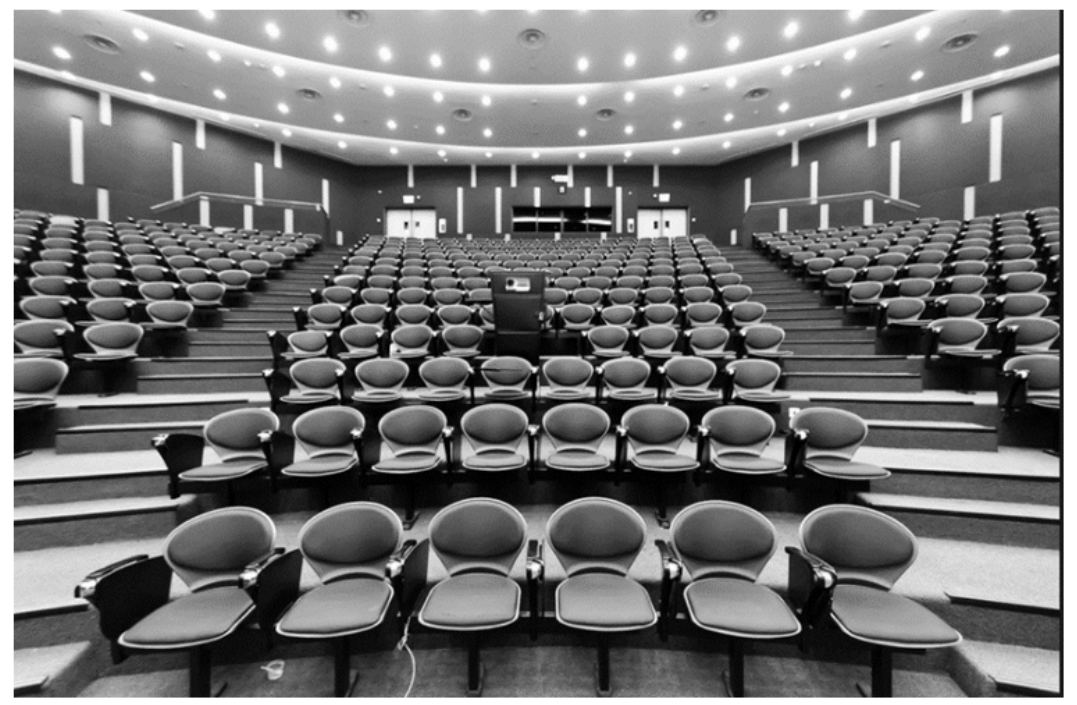

Figure 8: Chairs in Lecture Theatre LT7.

\section{Conclusion}

We have presented the methodology and the preliminary results for the large scale anthropometric studies using the 3D imaging systems. The study is ongoing and there will be more findings from the database that will be established. The study will also enable the construction of representative $3 \mathrm{D}$ digital human model for various age groups.

\section{Acknowledgement}

The authors would like to acknowledge the financial support from the Ministry of Education Academic Research Grant (R-265-000-474-112). 


\section{References}

[1] S. Ashdown, S. Loker, S., K.A. Schoenfelder \& L. Lyman-Clarke, "Using 3D scans for fit analysis" in Journal of Textiles and Apparel, Management and Technology, Vol. 4, no. 1, 2004, pp. 1-12..

[2] G. Bolstad, B. Benum \& A. Rokne, "Anthropometry of Norwegian light industry and office workers" in Appl. Ergon, Vol. 32, no. 3, 2001, pp. 239-246.

[3] C.G. Drury, "Case study: error rates and paperwork design" in Applied Ergonomics, Vol. 29, no. 3, 1998, pp. 213-216.

[4] C. Parcells, S. Manfred \& R. Hubbard, "Mismatch of classroom furniture and body dimensions. Empirical findings and health implications" in J Adolescent Health, Vol. 24, no. 4, 1999, pp. 265273.

[5] B. Sarghie, M. Costea, \& D. Liute, D, "Anthropometric study of foot using 3d scanning method and statistical analysis. International Symposium in Knitting and Apparel" in ISKA, lasi 21 - 22 June 2013.

[6] R. Trieb, A. Ballester, G. Kartsounis, S. Alemany, J. Uriel, G. Hansen, F. Fourlic, N. Sanguinetti \& M. Vangenabith, "EUROFIT - Integration, Homogenisation and Extension of the Scope of Large 3D Anthropometric Data Pools for Product Development" in 4th International Conference and Exhibition on 3D Body Scanning Technologies, Long Beach CA, USA, 19-20 November 2013.

[7] M.J. Wang, E.M.Y. Wang \& Y.C. Lin, "The anthropometric database for children and young adults in Taiwan The anthropometric database for children and young adults in Taiwan" in Applied Ergonomics. Ergon, Vol. 33, 2002, pp. 583-585. 